\title{
A Segunda Guerra Mundial de Tarantino: pastiche em Bastardos Inglórios
}

\author{
Francisco Renato da Silva Santos ${ }^{\mathrm{i}}$ \\ Charles Albuquerque Ponte ${ }^{\mathrm{ii}}$
}

\section{RESUMO}

Este artigo apresenta uma análise do filme Bastardos Inglórios (2009), de Quentin Tarantino, apontando os aspectos que o caracterizam como um pastiche dos filmes de guerra. Com base em Jameson (2006a), que instituiu esse conceito para se referir a um tipo de diálogo pós-moderno com outras obras, pretendemos demonstrar, através de um estudo comparativo, como ocorre o pastiche no filme de Tarantino, avaliando elementos como nostalgia, esquizofrenia e bricolagem que são característicos da arte contemporânea. A análise mostrará que Bastardos Inglórios apropria-se de várias referências do cinema, de diversos gêneros, ao mesmo tempo em que lança mão de artefatos estéticos dos filmes de faroeste, tocando a memória afetiva de seu público, além de apresentar características que o diferenciam de outros filmes de guerra, como a falta de compromisso com a historicidade, $o$ que nos permite caracterizá-lo como um pastiche desse gênero fílmico, especialmente dos que tratam sobre a Segunda Guerra Mundial.

Palavras-chave: Bastardos Inglórios; pastiche; nostalgia.

\begin{abstract}
This essay presents an analysis of Quentin Tarantino's movie Inglorious Basterds (2009), pointing out the aspects that characterize it as a pastiche of war films. Based on Jameson (2006a), who instituted the concept of pastiche to refer to a specific kind of postmodern dialog with other works, we intend to demonstrate, through a comparative study, how pastiche occurs in Tarantino's film, evaluating elements such as nostalgia, schizophrenia, and bricolage, that are typical of contemporary art. The analysis will show that Inglorious Basterds appropriates of various references from cinema, of several genres, while it uses aesthetic artifacts from western movies, tapping onto the affective memory of its audience, besides presenting characteristics that set it apart from other war films, such as the lack of commitment to historicity, which allow us to characterize it as a pastiche of that film genre, especially those dealing with World War II.
\end{abstract}

Keywords: Inglorious Basterds; pastiche; nostalgia.

\footnotetext{
${ }^{i}$ Doutorando em Letras pela Universidade do Estado do Rio Grande do Norte (UERN). Possui mestrado em Letras pela UERN (2011). Atualmente, é Técnico de Nível Superior na UERN, lotado no Campus Avançado de Pau dos Ferros (CAPF), no cargo de Secretário do Programa de Pós-Graduação em Ensino (PPGE). | https://orcid.org/0000-0001-5447-9836 | renatosantosuern@ gmail.com

ii Doutor em Teoria e História Literária pela Universidade de Campinas (2011). Possui mestrado em Letras (Inglês e Literatura Correspondente) pela Universidade Federal de Santa Catarina (2003). Atualmente é professor adjunto IV da Universidade do Estado do Rio Grande do Norte. | https://orcid.org/0000-0003-4342-6928 |ca_ponte@yahoo.com.br
} 
Uma característica marcante do diretor Quentin Tarantino é o seu ecletismo com relação aos gêneros dos filmes que dirigiu nos últimos anos, dos quais é possível citar vários exemplos, como: Pulp Fiction: Tempo de Violência (1994), do gênero policial; Kill Bill: Vol. 1 (2003) e Kill Bill: Vol. 2 (2004), que são no estilo de filmes de Kung Fu e faroeste; Bastardos Inglórios (2009), um filme de guerra; Django Livre (2012), que trata da escravidão norte-americana como um filme histórico; e Os Oito Odiados (2015), que é um filme de faroeste. É notório nos trabalhos do cineasta a presença de várias referências a outros filmes, longos diálogos e cenas de violência explícita. Poderíamos dizer que Tarantino procura dar a cada um desses gêneros fílmicos a sua marca própria que os diferenciam dos demais filmes do mesmo gênero, apresentando, assim, o seu próprio testemunho acerca de cada um desses gêneros fílmicos e, ao mesmo tempo em que se aproxima deles, ele também se afasta para comentá-los criticamente.

Ao tratar de Bastardos Inglórios (2009), percebe-se sua diferença com relação a outros filmes de guerra em uma das últimas cenas do filme, na qual dois membros do pelotão de soldados denominado de Bastardos Inglórios metralham impiedosamente os dois principais comandantes do Terceiro Reich, o ditador Adolf Hitler e o ministro da propaganda nazista Joseph Goebbels. Ironicamente, isso ocorre em um cinema durante a exibição de um filme pró-guerra, denominado $O$ orgulho da nação, que conta a história de um herói de guerra alemão. Nesse momento, o cinema, que estava lotado de outros importantes líderes nazistas, como Hermann Göring e Martin Bormann, é incendiado pela personagem Shosanna (Mélanie Laurent) e, em seguida, explode em decorrência de bombas plantadas pelos próprios Bastardos. Esse assassinato dos principais vilões da Segunda Guerra Mundial não é uma característica comum dos filmes desse gênero, que, com algumas exceções, procuram retratar da forma mais fiel possível os acontecimentos históricos, através de relatos de pessoas reais que viveram esse período.

O que Tarantino faz nessa sua versão de filme sobre a Segunda Guerra Mundial é o que Jameson (2006b, p. 44) chama de pastiche, que, assim como a paródia, é o "imitar de um estilo único, peculiar e idiossincrático, é o colocar de uma máscara linguística, é falar em uma linguagem morta". No então, o teórico diferencia esses dois tipos de intertextos ao dizer que "O pastiche é a paródia pálida, a paródia que perdeu o seu senso de humor" (JAMESON, 2006a, p. 23). Para Jameson, não é possível utilizar- 
se do termo paródia na pós-modernidade, porque com o esmagamento do sujeito burguês dos séculos passados, consequentemente não há um estilo singular original que possa ser ridicularizado. O que se tem é uma heterogeneidade de estilos ocasionada pela fragmentação da sociedade de modo que "cada indivíduo tenha se tornado um tipo de ilha linguística, separado de todos os demais" (JAMESON, 2006a, p. 22).

Linda Hutcheon (1991, p. 47), por outro lado, defende a existência da paródia pós-moderna ao revisar a origem morfológica da palavra: "o prefixo para- pode tanto significar 'contra' como 'perto' ou 'ao lado'”, ou seja, a paródia não tem por objetivo único a ridicularização do objeto parodiado, ela também permite o diálogo entre o passado e o presente. Essa visão de Hutcheon (1991) sobre o termo paródia aproxima-se bastante do conceito de pastiche defendido por Jameson (2006a), porém, há uma grande discordância entre esses autores com relação ao objetivo da arte pós-moderna no contexto em que ela se encontra. Para Hutcheon (1991, p. 56), essa volta ao passado estético "possibilita uma intervenção ideológica e social", permitindo uma resistência consciente do sujeito, do artista e seus produtos contra a dominação capitalista. Já para Jameson (2006, p. 23) o sujeito teve o seu individualismo e autonomia comprometidos pelo capitalismo, o que ele chamou de "a morte do sujeito", e a arte, consequentemente, tornou-se repetitiva e, segundo o autor, incapaz de modificar a realidade. É importante esclarecer que a crítica de Jameson (2006), não está voltada para as artes pós-modernas propriamente ditas, elas são o que são, fruto do momento histórico. O que o autor critica é o pós-modernismo em si, o momento histórico em que o capitalismo alcançou uma hegemonia nunca antes conseguida.

Neste artigo, a nossa preferência pelo uso do termo pastiche, utilizado por Jameson (2006), se explica pela característica do objeto analisado, pois entendemos que a obra de Tarantino se enquadra em uma perspectiva jamesoniana ao ridicularizar essa noção de que a linguagem modifica a realidade. Um exemplo disso é que a arte de Tarantino mata Hitler e outros comandantes do Terceiro Reich, mas não altera o passado e todas as atrocidades cometidas por eles.

Como se dá, então, o pastiche em Bastardos Inglórios? Percebemos a utilização do pastiche ao analisarmos o filme de Tarantino ao lado de outros filmes anteriores desse estilo, que trataram da Segunda Guerra Mundial, como O Resgate do Soldado 
Ryan (1998), de Steven Spielberg, e Operação Valkiria (2004), de Jo Baier ${ }^{1}$, por exemplo.

O Resgate do Soldado Ryan narra a história de um grupo de soldados americanos que tiveram a missão de resgatar um soldado com quatro irmãos mortos no conflito e levá-lo de volta para sua mãe. É uma das várias histórias de bravura e honradez que foram contadas pelo cinema sobre os soldados americanos, retratando-os como heróis. Em Bastardos Inglórios, o próprio título já denota a falta de honra dos anti-heróis comandados pelo tenente Aldo Raine (Brad Pitt), que são mostrados como cruéis, vingativos e sem caráter. A propósito, o objetivo do grupo de soldados não é ganhar a guerra ou libertar o mundo da tirania, mas, nas palavras de seu líder: "Uma vez em território inimigo, como um exército de guerrilheiros vamos fazer apenas uma coisa: matar nazistas". Na última cena do filme temos uma amostra da falta de caráter do protagonista, quando ele descumpre o trato que havia feito com o vilão do filme, o coronel nazista Hans Landa (Christoph Waltz). O coronel alemão havia descoberto o plano dos Bastardos e aprisionado o tenente Raine com o soldado Utivich, no entanto, deixaria o atentado ocorrer se fosse perdoado pelos seus crimes, recebesse a cidadania americana e fosse reconhecido como um dos responsáveis por encerrar a guerra. Segundo o trato, o coronel Landa e o seu operador de rádio, Hermann, levariam Raine e Utivish como prisioneiros até as linhas americanas, onde se entregariam aos Bastardos Inglórios. Nesse momento, porém, aproveitando-se da inversão da condição de poder, o tenente assassina Hermann, ordena que Utivish retire o escalpo do operador de rádio e desenha uma suástica na testa do coronel Landa com sua faca, uma marca do líder dos bastardos no decorrer do filme.

O Resgate do Soldado Ryan inicia com o protagonista interpretado por Tom Hanks desembarcando com o exército americano na Normandia, um dos momentos mais importantes da Segunda Guerra Mundial. É informada, inclusive, a data daquele momento, o que denota que o que será contado realmente aconteceu. A história do soldado Ryan é inspirada em um acontecimento real ocorrido com o soldado Frederick Niland que foi resgatado da guerra depois que seus três irmãos, que também lutavam no conflito, foram dados como mortos. Bastardos Inglórios, por outro lado, não tem intenção de retratar fatos reais, apesar de utilizar-se de personagens históricos como 
Hitler, Goebbels e Churchill. O filme de Tarantino apresenta uma versão alternativa dos eventos históricos, predominantemente ficcional.

Esse aspecto também diferencia Bastardos Inglórios de Operação Valkiria, filme alemão que conta a história real do atentado a bomba que tentou assassinar Hitler em 1944, orquestrado pelo Coronel Von Stauffenberg (Sebastian Koch) juntamente com um grupo do alto escalão alemão que planejava tomar o poder e render o país antes que fosse totalmente destruído pela guerra. Logo no início do filme, o diretor apresenta imagens reais da Segunda Guerra Mundial, o que é comum nesse gênero fílmico, para salientar a veracidade da história. Além disso, informa o local e a data de todos os eventos mostrados, e no dia do atentado a Hitler são informados os horários dos acontecimentos.

Outra marcante diferença entre os filmes de Tarantino e Baier é a forma em que são apresentados os personagens históricos Hitler e Goebbels. No início de Operação Valkiria, Hitler é mostrado no camarote de um teatro, sentado em uma poltrona dourada com seu uniforme marrom claro, tanto o figurino como a iluminação utilizada pelo diretor o destacam como uma figura poderosa em relação aos outros oficiais que ocupam o mesmo espaço. Nesse momento, o protagonista Stauffenberg demonstra sua idolatria com relação ao ditador ao comentar com sua noiva: "olhe nos olhos dele, ele está encantado" e "ele ama o exército". Depois, na cena em que planta a bomba na Toca do Lobo, Stauffenberg é apresentado ao Führer e, mesmo já o odiando, o trata com respeito e temor, fazendo a saudação nazista "Heil meu Führer". Por sua vez, Goebbels é apresentado em seu suntuoso palácio, como uma figura de poder e influência naquele regime. Inclusive, utiliza-se dessa influência para entrar em contato com Hitler e esclarecer ao oficial de Berlin que o Führer estava vivo, impedindo assim que o golpe liderado por Stauffenberg se concretizasse.

Com relação ao filme de Tarantino, Hitler e Goebbels são caricaturados e ridicularizados. Na primeira cena em que o Führer aparece, ele está suado e fala de maneira exaltada e irritada sobre os Bastardos Inglórios, em especial sobre o apelidado Urso Judeu. Percebemos nos diálogos do personagem com seus comandados que o ator que o interpreta utiliza-se dos trejeitos, exageros e idiossincrasias que o verdadeiro Hitler demonstra em seus famosos discursos filmados dirigidos às grandes multidões, como se o ditador tivesse sempre o mesmo comportamento eloquente não importando o 
contexto. Em certo momento, o diretor o focaliza de baixo para cima, em contraplongée, de forma que aparece um anão pintando a imagem do ditador na parede logo acima, na qual ele parece sereno e poderoso. Dessa forma, Tarantino realça o contraste entre a imagem que se tem do temido ditador apresentado na pintura acima e a caricatura desse personagem abaixo, gritando e gesticulando enfurecidamente com seus subordinados. Quanto ao personagem Goebbels, ele está frequentemente gargalhando de forma alta e debochada, diferente do Goebbels de Operação Valkiria, que mantém a postura séria. Na cena de Bastardos Inglórios em que o ministro é apresentado a Shosanna, ele está acompanhado de sua intérprete francesa, então, de repente, o diretor faz um corte para mostrar Goebbels transando com a intérprete de maneira grotesca.

Quando os dois homens mais poderosos do Terceiro Reich são colocados juntos em cena, no camarote do cinema de Shosana, assistindo ao filme Herói de uma Nação, a impressão de ridicularização dos dois personagens históricos fica ainda mais evidente. Ao ver o protagonista do filme em exibição matando os inimigos, os dois gargalham como se estivessem assistindo a uma comédia. O próprio astro do filme em exibição, o personagem Fredrick Zoller, que também estava no camarote, sente-se incomodado com a matança da tela, ao contrário da dupla que se divertia. Essa cena se torna ainda mais cômica quando Goebbels pergunta a Hitler sobre sua impressão do filme que ele patrocinou. Quando o ditador responde que foi o melhor filme que já assistiu, seu subordinado começa a chorar emocionado e é consolado pela sua amante. Ao mostrar esse momento íntimo dos personagens, Tarantino, ao mesmo tempo em que os ridiculariza e caricaturiza, também os apresenta de maneira mais humana, propensos a fragilidades emocionais, diferente da caracterização assustadora e superficial dos outros filmes do gênero. São exatamente essas fragilidades dos personagens que provocam a comicidade da cena. É interessante pensar, também, que a reação contrastante dos personagens Hitler, Goebbels e Zoller ao assistir ao filme O Orgulho da Nação, pode representar a peculiaridade do próprio Bastardos Inglórios, que possibilita diversas sensações aos seus espectadores, inclusive, e principalmente, o riso, algo inesperado para filmes sobre a Segunda Guerra Mundial.

Ao representar os nomes mais temidos da ditadura nazista como personagens cômicos, Tarantino demonstra a sua intenção de que não pretende abordar a Segunda Guerra Mundial de maneira realista e condizente com os fatos históricos. Como 
exemplo disso, podemos citar, novamente, que o enredo conta a morte de Hitler juntamente com todos os líderes do Nazismo no atentado organizado por Shosanna e os Bastardos, separadamente. Essa passagem do enredo de Tarantino pode ser interpretada como uma espécie de saciamento do desejo coletivo, inclusive do próprio diretor, de exterminar um dos personagens mais odiados da história, um desejo que é recalcado pelos filmes do gênero que obedecem à historicidade, como Operação Valkiria, em que Hitler consegue sobreviver ao atentado de Stauffenberg.

No início desse quinto e último capítulo de Bastardos Inglórios, denominado "A vingança do rosto gigante", Tarantino dá pistas do desfecho da história ao apresentar a personagem Shosanna se maquiando para realizar sua vingança contra os nazistas, enquanto a trilha sonora toca a música "Cat People", de David Bowie, lançada no ano de 1982. Essa anacronia da música denota novamente o desapego do diretor com relação à fidelidade histórica. A própria letra da música também é um presságio do que irá acontecer em seguida, na passagem que diz "E eu tenho apagado fogo com gasolina"2 (tradução nossa), e o fato de ser uma música de rock and roll dos anos 1980 traz essa carga de libertação pela rebeldia.

Na cena em questão, a cor vermelha é ressaltada pelo vestido da personagem e pela sua maquiagem. Na literatura, de acordo com Michael Ferber (2007, p. 169) “o vermelho é a cor do fogo, ouro e rosas; é a cor das faces quando elas se mostram embaraçadas, furiosas, ou cheias de saúde ou paixão. Também é a cor do sangue, claro ${ }^{3}$ [...]" (tradução nossa). Nessa cena, o vermelho pode representar a fúria vingativa de Shosanna e o prenúncio do fogo e sangue que está por vir. Primeiramente, a câmera filma em primeiro plano os olhos e depois a boca de Shosanna quando ela está passando seu batom vermelho. Em seguida, quando seu rosto é focalizado novamente, a personagem passa o blush vermelho com o dedo fazendo duas linhas horizontais em cada bochecha, um gesto bastante conhecido pelo atual contexto cultural como sendo característico dos índios, que pintam seus rostos antes das batalhas, e também dos soldados, como forma de camuflagem.

Ainda se referindo à música de David Bowie presente nessa cena, ela pode provocar outra sensação no espectador que é comum nas obras pós-modernas: a sensação de não saber que tempo ele está vivenciando na tela do cinema. Ele está na França ocupada nos anos 40 ou em um clipe de rock and roll nos anos 1980? Essa 
confusão temporal presente nas obras pós-modernas é o que Jameson (2006a) chama de esquizofrenia. Segundo o autor, esse é "um sintoma alarmante e patológico de uma sociedade que se tornou incapaz de lidar com o tempo e a história" (JAMESON, 2006a, p. 29). A grande quantidade de referências e intertextos que permeiam a arte pósmoderna não permite que se possa identificar o ponto de origem da referenciação provocando essa confusão temporal no consumidor dessa arte. Como ocorre aos espectadores de Bastardos Inglórios, a esquizofrenia é a incapacidade de localizar o objeto representado na linha do tempo. No entanto, como essa incapacidade é imediatamente associada ao pós-moderno, ao mesmo tempo em que o sujeito experimenta a desorientação temporal ao consumir a obra de arte, ele consegue reconhecer essa própria desorientação como pertencente a esse momento artístico, experienciando, assim, um paradoxo referencial.

Ainda segundo Jameson (2006a), esse fenômeno se explica pelo fato de vivermos sobre a imposição do capitalismo que transformou o passado em produto, que é rapidamente substituído por outro produto em evidência. A sociedade pós-moderna, então, passou a "perder a capacidade de reter o seu próprio passado, começou a viver em um presente perpétuo e em uma mudança perpétua, que obliteram as tradições do tipo preservado, de um modo ou de outro, por toda a informação social anterior" (JAMESON, 2006a, p. 44). A indústria cultural aproveita-se desse fenômeno para, através da velocidade de informação, confundir o seu público, que não percebe se está consumindo um produto repetido, já que perdeu a sua localização temporal.

Esse aspecto se refere mais uma vez ao pastiche, ou, mais precisamente, a uma prática específica de pastiche, que Jameson (2006a) denominou de "cinema nostálgico". Essa modalidade de cinema oferece ao público uma volta no tempo, para uma geração específica que ficou internalizada em sua memória afetiva. Isso não quer dizer que o "cinema nostálgico" se refere apenas a filmes sobre o passado, mas também àqueles que, em sua composição estética, relembram o espectador de filmes ou séries que ele costumava assistir na sua juventude. Em uma sociedade bombardeada de informações em que as pessoas têm dificuldade de se apegar a novas histórias, a indústria cultural utiliza-se dessa nostalgia para agregar valor a seus produtos.

Bastardos Inglórios pode ser considerado um exemplar desse "cinema nostálgico", não só pelo fato de contar uma história ambientada no passado, mas, 
principalmente, por apresentar artefatos estéticos de um gênero fílmico que se tornou bastante popular e fez bastante sucesso nos anos 1950 e 1960, e até os dias atuais, sendo considerados como clássicos do cinema: os filmes de faroeste ou western. Esses filmes são ambientados no oeste americano no período em que o governo dos Estados Unidos promoveu a ocupação dessa região, distribuindo loteamentos de terra para quem chegasse primeiro. Para isso, promoveu vários genocídios contra os índios que viviam nesses territórios, para abrir espaço para a ocupação branca. Era um ambiente sem lei, que favorecia os mais fortes, o que inspirou a criação de grandes histórias de mocinhos contra bandidos, cowboys contra índios, anti-heróis em busca de justiça etc.

Para ilustrar as características do Bastardos Inglórios que remetem o público aos filmes de faroeste, utilizaremos como paralelo o filme que é considerado por muitos como a principal obra de um dos maiores diretores do gênero, Era uma vez no Oeste (1968), do italiano Sérgio Leone. Tarantino é, inclusive, um grande fã de filmes de faroeste, tanto que fez uma lista dos seus vinte favoritos para o site The Spaghetti Western Database, na qual Era uma vez no Oeste estava incluído. Não é à toa que o diretor se utiliza de várias referências desse gênero nos seus filmes, aproveitando-se também de sua popularidade para atrair o público da cultura de massa.

Um atributo marcante de Bastardos Inglórios que nos lembra os filmes de faroeste são os apelidos atribuídos aos anti-heróis e ao vilão do filme. Há, inclusive, um diálogo na cena em que o coronel Landa está interrogando o tenente Reines e Utivich, em que os personagens comentam sobre seus apelidos:

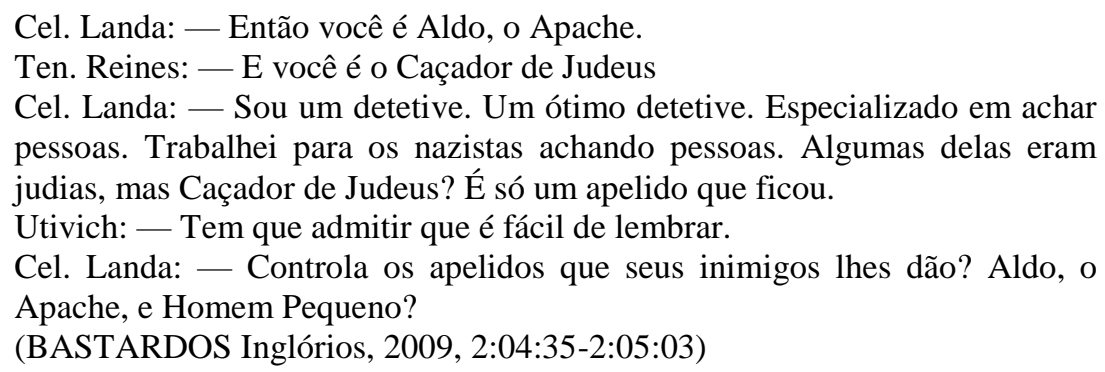

Outro personagem do filme que também tem um apelido marcante é o sargento Donny Donowitz, conhecido como Urso Judeu. Ele adquiriu essa fama por esmagar os cérebros dos nazistas com um bastão de beisebol. Esse apelido tornou-se tão forte entre 
os alemães, que o próprio Hitler dá ordem aos soldados residentes na França de não mais se referirem ao sargento Donowitz como Urso Judeu.

Também temos a explicação da origem do apelido de Aldo, o Apache, na cena em que o tenente Raine se apresenta para o grupo de soldados que seriam conhecidos como Bastardos Inglórios: "Sou descendente direto do explorador Jim Bridger. Significa que tenho sangue de índio. E nosso plano de batalha será o da resistência apache". Os índios apaches eram conhecidos pela sua voracidade na guerra e tinha o hábito de escalpelar, ou seja, retirar o couro cabeludo de seus inimigos mortos, como forma de ganhar prestígio na tribo. Esse é outro motivo para o apelido do tenente Raine, que, na mesma cena em que se apresenta aos soldados, exige deles que lhes tragam os escalpos dos nazistas mortos: "Sob o meu comando, assumem uma dívida. Uma dívida pessoal comigo. Todo homem sobre meu comando me deve 100 escalpos nazistas. E eu quero meus escalpos".

Como dissemos, nos filmes de faroeste os personagens normalmente conhecidos por seus apelidos marcantes. Em Era uma Vez no Oeste, o principal "mocinho" da história, interpretado por Charles Bronson, é conhecido apenas pelo seu apelido, Harmonica (gaita, em português), que inclusive foi dado por outro personagem importante da história, Cheyenne (Jason Robbards). O verdadeiro nome de Harmonica não é nem citado durante todo o filme, e esse mistério que envolve o personagem faz parte de sua caracterização. A própria história do vilão Frank (Henry Fonda), gira em torno de descobrir quem é, de onde veio e qual motivo tem para querer matá-lo.

O personagem Cheyenne, assim como Aldo, o Apache, também tem um caráter questionável, já que é um bandido fugitivo. Uma característica marcante dos filmes de Leone, que inclusive é umas das atualizações estilísticas do diretor ao western clássico americano, é essa presença de anti-heróis, de mocinhos que são bandidos: "[...] o herói foi transformado em um anti-herói amoral, com vícios e maneirismos; [...] as motivações dos anti-heróis eram a vingança e o dinheiro e não mais uma causa ética e libertadora" (GOMES \& VADICO, 2018, p. 98). Outra semelhança com Aldo, o Apache, é que Cheyenne também era o nome de uma tribo indígena americana que foi dizimada pelo exército americano durante a ocupação do oeste. Não fica claro, porém, se esse é realmente o nome verdadeiro do personagem ou um apelido. 
O motivo para o apelido de Harmonica é que o personagem carrega consigo uma gaita, que no final do filme é revelado que pertencia ao seu irmão que fora assassinado por Frank. Esse instrumento configura-se como uma peça-chave para a caracterização do personagem. Quase em todos os momentos que ele aparece, ele é anunciado pelo som da gaita que ele mesmo produzia.

A utilização do som para anunciar a chegada de um personagem e para caracterizá-lo também foi utilizada por Tarantino em uma das cenas mais marcantes de Bastardos Inglórios. Quando o Raine chama o Donowitz para executar um sargento nazista que se recusou a mostrar a localização de uma patrulha alemã, primeiro ouve-se o som do bastão de basebol batendo na parede, vindo de dentro de um túnel. À medida em que as batidas do bastão vão ficando mais rápidas, a câmera vai se aproximando da entrada do túnel, intercalando com o primeiro plano do rosto do sargento que será morto e de outro soldado alemão que está chorando de pavor, até que o Urso Judeu aparece com o bastão de basebol no ombro. Percebemos, também, que o apelido atribuído ao sargento Donowitz relaciona-se mais à agressividade com que ele mata suas vítimas e ao temor psicológico que ele provoca nos nazistas do que propriamente aos seus atributos físicos, já que, apesar de forte, é um homem relativamente pequeno, se comparado a alguns dos outros membros do pelotão.

Nessas cenas mencionadas dos filmes de Leone e de Tarantino, o som também tem a função de amplificar a tensão desses momentos, que é denotada pelo uso da câmera em primeiro plano que enquadra os rostos dos personagens envolvidos nessa tensão. Segundo Martin (2003, p. 39), “é o primeiro plano do rosto humano que se manifesta melhor o poder de significação psicológico e dramático do filme". O uso dessa câmera foi outra característica marcante introduzida por Leone aos filmes de faroeste. Tanto Leone como Tarantino costumam utilizar esse recurso não apenas para focalizar os rostos, mas também as mãos e as armas dos personagens.

Como já dissemos, Tarantino utiliza-se bastante das referências de outros filmes para compor seus enredos, não só de filmes de faroeste, mas diversos outros estilos cinematográficos. Essa bricolagem de estilos que são colocados juntos para produzir uma obra é outra característica comum na arte pós-moderna. Segundo Jameson (2006a, p. 25), "isso significa que a arte pós-moderna ou contemporânea se pautará pela própria arte de um modo novo". 
A bricolagem é outro aspecto do pastiche que está bastante presente em Bastardos Inglórios. Além das referências dos filmes de faroeste, a narrativa faz alusão aos filmes de espião, especialmente na cena em que os Bastardos aparecem disfarçados de profissionais do cinema italianos, vestidos de smoking como nos filmes da franquia de 007. O figurino utilizado por Brad Pitt destaca-se nessa cena: ele veste um smoking branco com um cravo na lapela, o mesmo utilizado por Sean Connery ao interpretar o espião James Bond na década de 1960. A peça virou um ícone da franquia 007, por isso, torna-se evidente a referência feita por Tarantino nessa cena: uma referência sarcástica, assim como a personalidade do tenente Aldo Raine.

Bastardos Inglórios também faz menção aos filmes de detetive, nos quais os criminosos são descobertos através da investigação pericial e interrogação das testemunhas e dos suspeitos. O coronel Landa utiliza-se desses métodos investigativos para, por exemplo, descobrir que a atriz Bridget von Hammersmark estava envolvida no tiroteio no bar que acabou com a morte de soldados alemães e membros dos Bastardos. Ao investigar a cena do crime, encontra um par de sapatos femininos e um autógrafo dado pela atriz a um soldado alemão. Outra técnica de investigação utilizada pelo coronel Landa é o profiling criminal, em que o detetive busca traçar o perfil psicológico dos procurados, característica dos filmes da franquia de Hannibal, por exemplo. Isso é notado na primeira cena do filme em que ele descobre a família de Shosana escondida no assoalho da casa do senhor LaPadite. Nessa cena, o coronel Landa afirma que é bemsucedido na procura de judeus porque: "ao contrário de muitos dos soldados alemães, eu posso pensar como um judeu, enquanto eles limitam-se a pensar como alemães".

Há ainda uma notável referência aos contos de fada quando o coronel Landa interroga a atriz Bridget von Hammersmark e prova que ela estava trabalhando para os Bastardos colocando o sapato, que havia encontrado no bar onde houve o tiroteio, no pé da atriz. Essa cena faz uma clara menção à história da Cinderela, em que o príncipe encantado descobre quem é a sua amada através do sapato que ela perdeu no baile do castelo.

Diante de todas essas referências presentes em Bastardos Inglórios, não devemos interpretar esse fenômeno como uma falha do diretor, pelo contrário, esse filme deve ser reconhecido como uma obra típica de um período em que se vive em "plena 'intertextualidade'" (Jameson 2006b, p. 47), ou seja, em que a linguagem 
artística é permeada por uma vasta quantidade de intertextos. Nessa arte contemporânea, Tarantino marca sua capacidade característica de utilizar e misturar essas referências criativamente, de forma que elas sejam simultaneamente desiguais e harmônicas, pois constroem um todo mais ou menos homogêneo. Ao utilizar-se de várias referências do cinema, de diversos gêneros, ao mesmo tempo em que lança mão de artefatos estéticos dos filmes de faroeste, tocando a memória afetiva de seu público, Tarantino desenvolveu uma obra fílmica que pode ser caracterizada como um pastiche dos filmes de guerra, especialmente dos que tratam sobre a Segunda Guerra Mundial.

\section{Referências}

BASTARDOS Inglórios. Direção: Quentin Tarantino. New York: Universal Pictures e The Weinstein Company, 2009. 1 DVD (153 min.).

ERA uma vez no Oeste. Direção: Sergio Leone. Los Angeles: Paramount Pictures, 1968. 1 DVD (175 min.).

FERBER, Michael. A Dictionary of Literary Symbols. Second edition, New York: Cambridge University Press, 2007. Disponível em:

https://www.emeraldinsight.com/doi/10.1108/09504120810859792. Acessado em $30 \mathrm{de}$ dezembro de 2020.

GOMES, Delson de Matos; VADICO, Luiz Antonio. Uma pausa para o cigarro: as interações com o cigarro no Spaghetti Western de Sergio Leone. Rebeca - Revista Brasileira de Estudos de Cinema e Audiovisual, São Paulo, v. 7, n. 2, p. 11 - 175, 2019. Disponível em: https://rebeca.socine.org.br/1/article/view/508/322. Acessado em 30 de dezembro de 2020

HASELBECK, Sebastian. Quentin Tarantino's Top 20 favorite Spaghetti Westerns. The Spaghetti Western Database, 2018. Disponível em: https://www.spaghettiwestern.net/index.php/Quentin_Tarantino's_Top_20_favorite_Spaghetti_Westerns Acessado em: Acessado em 30 de dezembro de 2020.

HUTCHEON, Linda. Poética do pós-modernismo: história, teoria, ficção. Trad. Ricardo Cruz. Rio de Janeiro: Imagino Ed., 1991.

JAMESON, Fredric. A virada cultural: reflexões sobre o pós-modernismo. Trad. Carolina Araújo. Rio de Janeiro: Civilização Brasileira, 2006a.

JAMESON, Fredric. Pós-modernismo: a lógica cultural do capitalismo tardio. $\underline{2}^{\mathrm{a}}$ ed. São Paulo: Ática, 2006 b.

MARTIN, Marcel. A linguagem cinematográfica. Trad. Paulo Neves. São Paulo: Brasiliense, 2003. 
OPERAÇÃO Valkiria. Direção: Jo Baier. Alemanha: Flashstar, 2004. 1 DVD (92 min.).

O RESGATE do Soldado Ryan. Direção: Steven Spielberg. Los Angeles: Paramount Pictures e Dreamwork Pictures, 1998. 1 DVD (169 min.).

Recebido em: 11/01/2021

Aceito em: 02/02/2021

\footnotetext{
${ }^{1}$ A escolha desses dois filmes como contraste ao de Tarantino se justifica, não apenas pela popularidade dessas histórias, mas também pelos diferentes focos narrativos que eles apresentam, o de Spielberg no ponto de vista americano na representação do soldado americano, e o de Baier no ponto de vista alemão na representação dos ditadores alemães.

2 "And I've been putting out fire with gasoline".

3 "Red in literature is the color of fire, gold, and roses; it is the color of faces when they show embarrassment, anger, or the flush of health or passion. It is also the color of blood, of course [...]".
} 